\title{
WITHDROWN: Effect of smoking habit on crestal bone height in maxillary sinus augmentation with bone grafts
}

\author{
Javier Carreño-Carreño ${ }^{1}$, Gerardo Gómez-Moreno ${ }^{2}$, Antonio Aguilar-Salvatierra ${ }^{3}$, Cristina Menén- \\ dez-López-Mateos ${ }^{4}$, Adriano Piattelli ${ }^{5}$, Mario Menéndez-Núñez ${ }^{6}$ \\ ${ }^{1}$ Assistant Professor, Faculty of Dentistry, European University of Madrid, Spain \\ ${ }^{2}$ Chairman of Pharmacological Research in Dentistry Group, Full Professor of Special Care in Dentistry, Faculty of Dentistry, \\ University of Granada, Granada, Spain \\ ${ }^{3}$ Pharmacological Research in Dentistry Group, Faculty of Dentistry, University of Granada, Granada, Spain \\ ${ }^{4}$ Collaborator, Department of Orthodontics, Faculty of Dentistry, University of Granada, Granada, Spain \\ ${ }^{5}$ Full professor, Department of Medical, Oral and Biotechnological Sciences, University of Chieti-Pescara, Chieti, Italy \\ ${ }^{6}$ Professor of Department of Orthodontics, Faculty of Dentistry, University of Granada, Granada, Spain
}

\footnotetext{
Correspondence:

Facultad de Odontología

Campus Universitario de Cartuja

Colegio Máximo $s / n$

E-18071 Granada, Spain

aaguilar@ugr.es
}

Please cite this article in press as: Carreño-Carreño $\mathrm{J}$, Gómez-Moreno G, Aguilar-Salvatierra A, Menéndez-López-Mateos C, Piattelli A, Menéndez-Núñez M. Withdrown: Effect of smoking habit on crestal bone height in maxillary sinus augmentation with bone grafts. Med Oral Patol Oral Cir Bucal. (2019), doi:10.4317/medoral.22439

\begin{abstract}
In relation to the article with reference "Carreño-Carreño J, Gómez-Moreno G, Aguilar-Salvatierra A, MenéndezLópez-Mateos C, Piattelli A, Menéndez-Núñez M. Effect of smoking habit on crestal bone height in maxillary sinus augmentation with bone grafts. Med Oral Patol Oral Cir Bucal. (2019), doi:10.4317/medoral.22439", published in Oral Medicine Oral Pathology and Oral Surgery in the modality "AHEAD OF PRINT - article in press", the authors mention that "The study was conducted according to the STROBE (Strengthening the Reporting of Observational Studies in Epidemiology) Statement". However, and based on the opinion of several expert reviewers who have re-evaluated the article, it is considered that although "there has not been plagiarism", these STROBE criteria are not adequately met. In addition, the mentioned article is very similar to two articles that have already been published by the same authors in Clinical Oral Implants Research. The sample is the same; many data are repeated; and the only difference is the inclusion of a variable (smoking), which does not exert a significant effect. This outcome therefore would not justify publication of the paper in the journal. Retraction of the article is therefore decided.
\end{abstract}

